
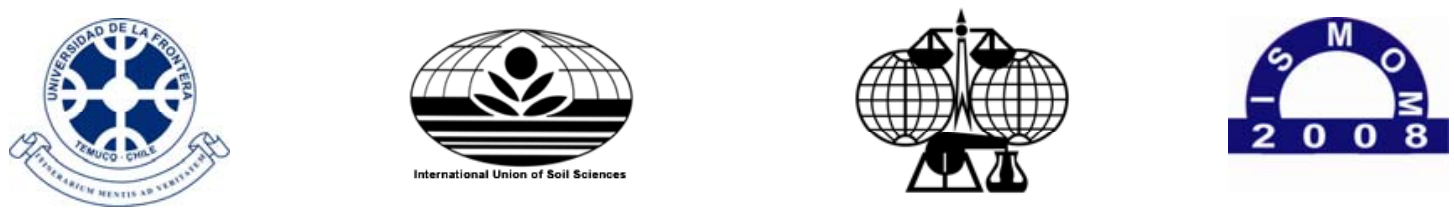

$5^{\text {th }}$ International Symposium ISMOM 2008 - November $24^{\text {th }}-28^{\text {th }}, 2008$ - Pucón, Chile

Plenary papers

\title{
Impacts of Metals and Metalloids on Soil Microbial Diversity and Ecosystem Function
}

David Crowley*

Department of Environmental Sciences, University of California, Riverside, USA 92521.

*E-mail: crowley@ucr.edu

Metal and metalloid concentrations in soil exert an enormous influence on the diversity, composition, and activity of soil microorganisms that carry out essential ecosystem services. At low concentrations, microorganisms can compete for essential trace elements that are required to support their growth and in this manner affect plant nutrition and disease through the production of metal chelators. At high concentrations, the toxic effects of metals result in reduced microbial diversity and altered rates of key biological processes that underlie ecosystem function. The latter is now of great concern as large land areas across the globe have become contaminated with metals from land application of wastes and atmospheric deposition of heavy metals. An understanding of how plants, soils, organic matter, and microorganisms influence metal transformations in the rhizosphere is thus critical for managing soils to assure the long term protection of soil quality, food safety, and ecosystem function.

One of the major difficulties in making practical management decisions with respect to metal pollution for different types of soils has been our inability to derive bioindicators of soil quality that can provide indices of soil quality across the landscape at different scales and over time. Ecosystems respond very differently to acute and chronic metal toxicities depending on their chemical properties and prior exposure histories. Toxicities are particularly influenced by physico-chemical conditions in soils that influence the bioavailability of metals and metalloids to plants and microorganisms. Nonetheless, the dynamic nature of microbial communities, which respond much faster to changes in management practices than do soil physical and chemical properties enables us to use bioindicators as a sensitive tools for predicting possible long term changes in soil properties. From a land management perspective, it is critical that soil microbiologists offer appropriate bioindicators for use in measuring the impacts of soil pollution on soil biological properties and extend knowledge as to how specific bioindicators may reflect long term changes in soil quality that can be used to guide land management practices and remediation of contaminated soils.

\section{Responses of Microbial Communities to Metal Contamination}

The microbial community concept is based on the interactions among in all of the various species of bacteria, fungi, protozoa, and microfauna that carry out the various broad level functions of the soil, ranging from nutrient cycling to organic matter formation, and plant disease protection. Differences in the species composition of various soils are linked to changes in soil biological properties that in turn affect the long term chemical and physical properties and ability to support plant growth. Among the most basic functions are respiration 

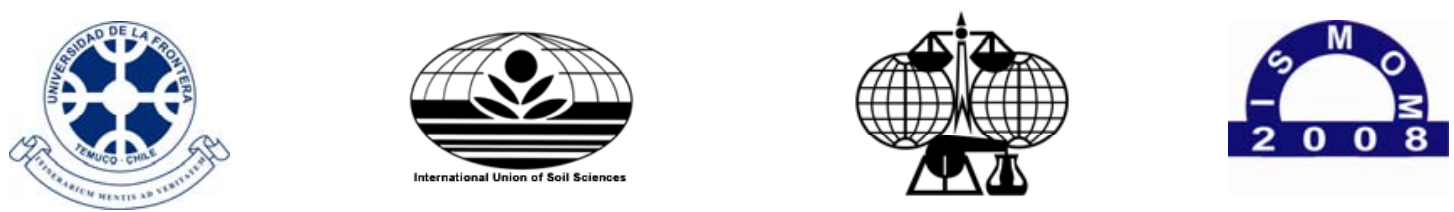

$5^{\text {th }}$ International Symposium ISMOM 2008 - November $24^{\text {th }}-28^{\text {th }}, 2008$ - Pucón, Chile

Plenary papers

and organic matter formation, both of which are affected by metal contamination. Acute responses of microbial populations to metal toxicities include reduction in species diversity, the biomass of microorganisms, and an increase in the respiration rate. As microbial respiration controls the turnover and accumulation of carbon, the measurement of the soil respiration rate per unit of biomass, also known as the metabolic quotient (Anderson and Domsch, 1993), is one of the most sensitive response of microbial communities to metal contamination. As the metabolic quotient increases, carbon is released at a faster rate from the soil, leading to lower organic matter accumulation that over years can affect the soil structure and cation exchange capacity. In turn loss of soil structure affects aeration, bulk density, and root growth which then leads to lower primary productivity. Loss of soil carbon due to metal pollution is also a concern for global climate change as the soil is a major reservoir of carbon and is being managed in national carbon budgets to offset anthropogenic releases of carbon to the atmosphere.

Going beyond the biomass and respiration, one of the principle effects of metal pollution is the loss of biodiversity (vanBeelen and Doelman, 1997). The soil microbial community consists of assemblages of tens of thousands of species of archaea, bacteria, and fungi, all of which occupy different niches in the soil and carry out various biogeochemical processes and ecosystem functions. The large diversity of species as compared to the list of the soils most basic functions has led to the concept of functional redundancy in which many different species operating in guilds are presumed to function as interchangeable members of functional guilds. As long as there are many different species that carry out the same function, i.e. cellulose degradation or plant hormone production, then the process is likely to proceed over the full range of environmental conditions that occur in the soil. On the other hand, the functional diversity of the soil provides an index of the number and types of substrates that are utilized by the predominant microbial populations. The latter can be measured using specially developed assays such as Biolog plates or in-situ substrate additions that can be measured colorimetrically using dehydrogenase activity or by measurement of substrate induced respiration rates.

One of the major concerns arising from studies of metal contamination is the loss of both substrate diversity and functional redundancy that occurs as an effect of metal toxicity. A primary function of soil microbial communities is to degrade all of the natural carbon substrates that enter the soil or that are produced as a result of microbial growth. The chemical diversity of soils is enormous with many thousands of plant and microbial secondary metabolites undergoing transformation and degradation. Many of these substances are potentially toxic to plants when they occur at elevated concentrations, and one of the functions of slow growing, oligotrophic population of bacteria is thought to be the degradation of chemicals that occur at low concentrations. The vast majority of these bacteria are nonculturable under standard laboratory conditions due to their extremely slow growth rates and requirement for special growth media and conditions. Thus it is very difficult to assess the impact of metals on the oligotrophic population. Nonetheless, early work conducted using culture based methods has shown the impact of metals on the functional diversity of the soil bacterial population (Figure 1). In the study illustrated here, the number of species that could grow on selected chemicals was determined for soil bacteria that could 

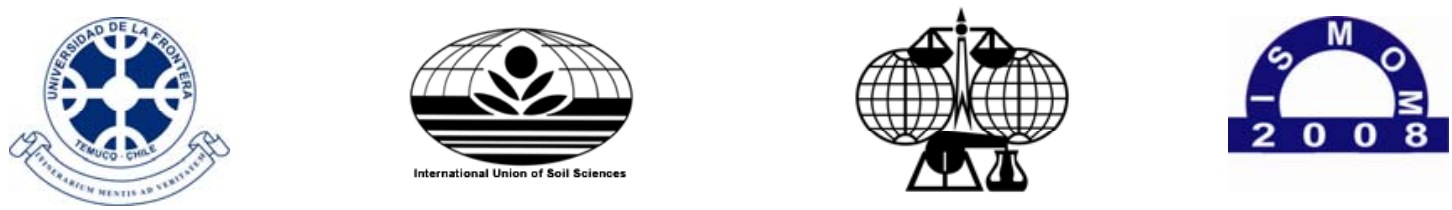

$5^{\text {th }}$ International Symposium ISMOM 2008 - November $24^{\text {th }}-28^{\text {th }}, 2008$ - Pucón, Chile

Plenary papers

grow on agar amended with the chemical in the presence and absence of zinc. In all instances, the metal tolerant population represented a subset of bacteria such that metal contamination reduced the overall functional diversity or numbers of species that could grow on individual chemicals. In some instances, there was a complete lack of metal tolerant species, which if extended to the unculturable population means that the soil may lose the ability to carry out this particular degradative function.

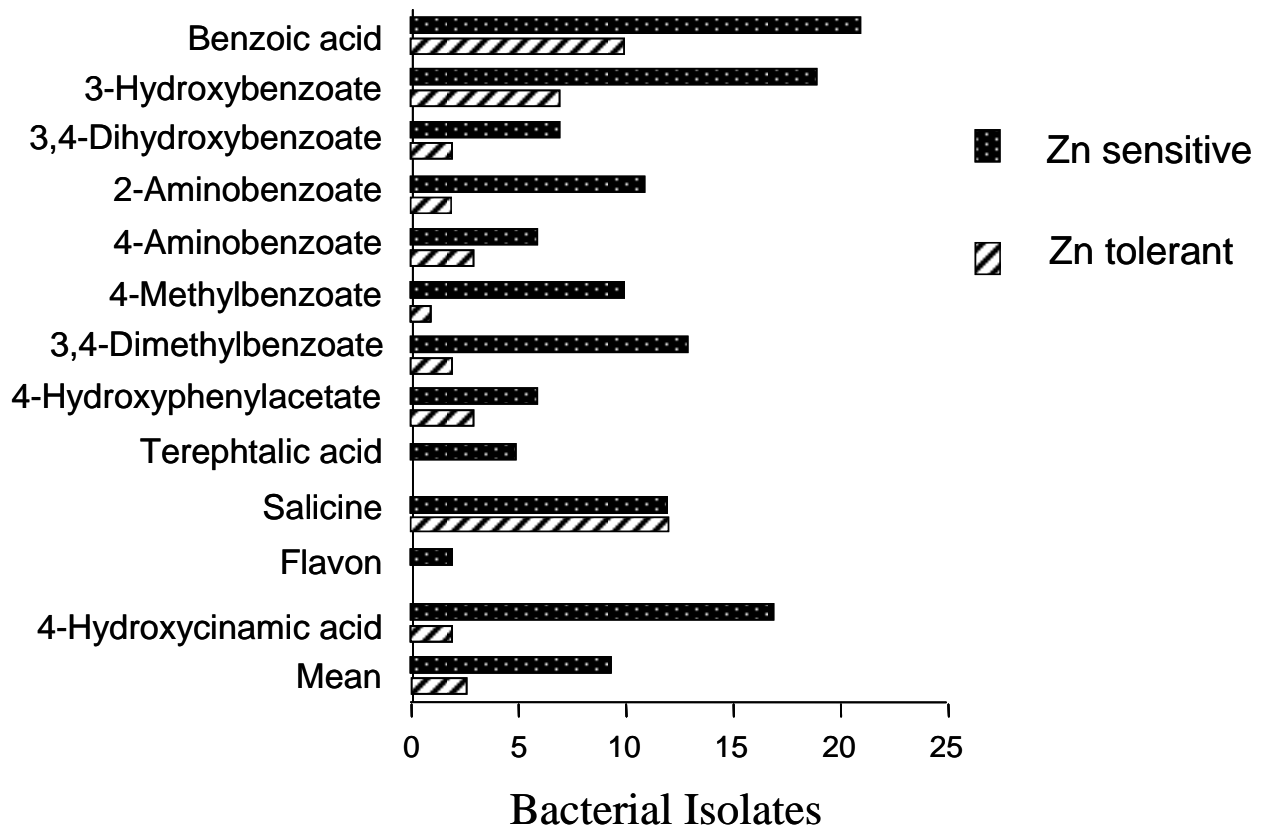

Figure 1. Loss of metabolic diversity in microbial communities exposed to zinc during enrichment culture on selected carbon substrates. Figure adapted from Doelman et al., 1994).

The idea that loss of functional diversity may impair the stress tolerance of the soil bacterial community has been examined in a series of studies in which soils were partially sterilized using heat or were exposed to various stressors such as metal contamination to determine the overall impact on the rate of degradation of various substrates and other measures of microbial activity (Degens et al., 2001; Griffiths et al., 2000, 2001). Here, the primary concern centers on the property of microbial community resilience, which is the ability to recover from various normal shocks to the microflora that occur as a result of normal fluctuations in the environment. These studies have clearly shown that loss of microbial diversity lead to loss of resilience and declines in ecosystem function. The major question that arises from this body of research is to what extent can microbial diversity be reduced before ecosystem functions are affected, and what degree of loss is tolerable from a regulatory perspective (Dahlin et al., 2001). 

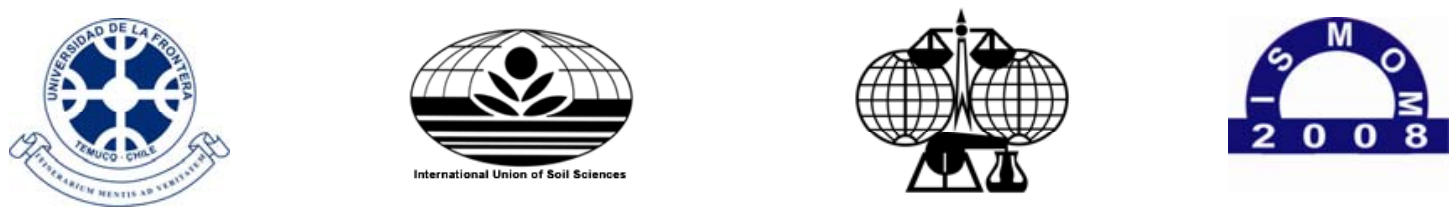

$5^{\text {th }}$ International Symposium ISMOM 2008 - November $24^{\text {th }}-28^{\text {th }}, 2008$ - Pucón, Chile

Plenary papers

In addition to broad scale functions that are carried out by guilds that are comprised of tens to hundreds of species, metals may also affect so called keystone microorganisms that carry out very specific functions and that are comprised of narrow phylogenetic groups of species. For example, ammonia oxidation and symbiotic nitrogen fixation are carried out by very specialized bacteria. Agriculture is highly dependent on the use of rhizobium bacteria that fix nitrogen in association with legumes and the efficiency of various strains of symbiotic bacteria in carrying out this process is of concern for optimizing the rates of $\mathrm{N}$ fixation. In this case, the bacteria are classified both by their infectivity (ability to colonize plant roots) and affectivity (ability to fix nitrogen). Research by McGrath and coworkers (Castro et al., 2002) have shown that strains with good infectivity may remain, but that these strains may be less or completely ineffective for fixing nitrogen. The level of metal tolerance of effective strains is thus proposed as a measure for setting the upper limits of acceptable metal loading and soil contamination.

\section{Bioindicators of Soil Quality and Metal Contamination}

A review of the 52 environmental/soil monitoring programs available world-wide (Winder 2003) shows that the vast majority of programs utilize a minimum dataset to describe soil quality. Of these programs, the vast majority only measures of soil chemical characteristics such as $\mathrm{pH}$, C fractions, NPK, EC, CEC, half use soil physical variables such as moisture, PSA, and penetration resistance and less than one third measured soil biological data, almost exclusively microbial biomass or enzyme activity. Nonetheless, its is now increasingly acknowledged that biological indicators will extend the utility of soil quality assessment in soils that are undergoing more subtle, management-induced changes (Filip, 2202; Neilson and Winding 2002). The ideal tool must also be spatially and temporally defined and account for heterogeneity at a given spatial and temporal scale (Conroy et al., 1996). Most importantly, the information generated by these tools needs to have practical utility at a scale where it is possible to make recommendations on different soil management practices.

Bioindicators used to assess soil microbial quality can include single, holistic measures of the overall microbial community such as biomass, respiration rates, metabolic quotient and enzyme activities or can include measures that have a multiple number of variables to describe the structural and or functional composition of a soil microbial community. Examples of multiparametric measures include phospholipid fatty acid (PLFA) profiles (Baath et. al., 1998), 16S rRNA gene methods such as PCR-DGGE and TRLFP, and substrate diversity assays. Single parameters provide an integrative estimate of the entire microbial community and are relatively widely used because they are easy to measure, are relatively inexpensive and they can be incorporated into Analysis Of Variance (AOV) linear models. However, such measures have been increasingly criticized for being inconsistent and demonstrate a high coefficient of variation in response to seasonal climatic changes (Sojka et al., 1999; Gil-Sotres et al., 2005).

Any one method for characterizing microbial community structure and function provides only a limited perspective and are therefore subject to over and under interpretation in assessing soil biological responses to different to environmental variables. For example, soil 

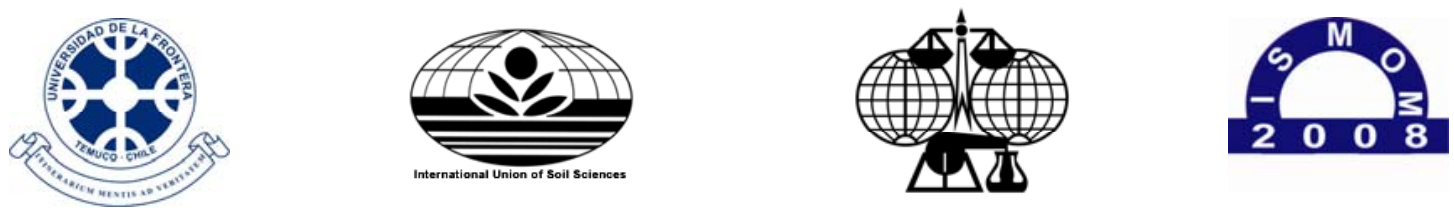

$5^{\text {th }}$ International Symposium ISMOM 2008 - November $24^{\text {th }}-28^{\text {th }}, 2008$ - Pucón, Chile

Plenary papers

respiration and may reflect the activity of diverse microorganisms on many different substrates, or growth of a few species on a particular substrate such as cellulose. Although this short-coming can be improved by polyphasic measurements in which the investigator looks for consistency across a range of methodologies such as enzymes, respiration, biomass, and others, the interpretation of polyphasic data is often speculative. Alternatively, multiparametric data attempts to describe community structures and functions that use multiple variables within one category. These data can include biochemical, catabolic, and genetic fingerprints of the microbial communities and can be based on 30 to 100 or more variables within the one methodology. Unlike the straightforward AOV models used for single parameter data, multiparametric data are highly dimensional and need to undergo statistical procedures to reduce dimensionality before they can be incorporated into models. They tend therefore to have restricted use. Despite these difficulties, there are now many bioindicators that have potential application for assessing the impacts of heavy metals on soil biological function and for guiding the development of policy to guide land application of metal waste and criteria for restoration of metal contaminated soils (Tandy et al., 2005).

\section{Application of Artificial Neural Networks for Evaluation of Bioindicators}

In recent years, one of the most powerful approaches that has emerged for integrating disparate types of qualitative and quantitative data is the use of artificial neural networks (ANN) that employ machine learning to extract and recognize patterns in relationships among descriptive variables (Schultz and Wieland 1997; De la Rosa, Mayol et al. 2004). Although not widely used yet for analysis of soil quality variables, there has been increasing application of ANN for modeling of data sets used to describe individual soil physical, chemical, and biological properties during the past ten years. ANNs are particularly useful for extracting patterns among data sets in which there may be complex nonlinear interactions that cannot be detected with traditional methods for multivariate analyses. Among the range of applications that have been realized, ANNs have been used to classify soil structure and physical properties (Levine, Kimes et al. 1996; Chang and Islam 2000), for soil and vegetation mapping (Tan and Smeins 1996; Deadman and Gimblett 1997), prediction of nonpoint source pollution (Muleta and Nicklow 2005), for prediction of soil salinization (Patel, Prasher et al. 2002), and for predicting soil organic carbon accumulation under different land use schemes (Somaratne, Seneviratne et al. 2005).

For studies on soil biological data, neural network analysis (ANN) has most recently been used to relate microbial biomass and 16S rRNA gene banding patterns to soil texture and other chemical properties (Lentzsh, Wieland et al. 2005; Ramadan, Hopke et al. 2005). With ANN, multidimensional data can be reduced in dimensionality by a combination of self organizing maps (SOM) which are a type of neural network, and principle components analysis. Results generated from this approach provide a 2- or 3-dimensional map of clusters that reflect relationships between variables and site locations. The maps can be used to explore the influence of environmental variables on biological indicators (Kampichler et al., 2000; Noble et al., 2000; Lentzsh et al., 2005). This information can be used to identify key variables and can be used for forecasting changes in response variables over time. Most 

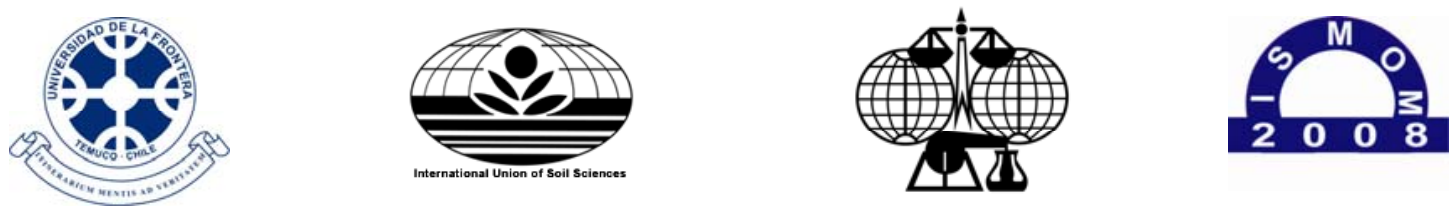

$5^{\text {th }}$ International Symposium ISMOM 2008 - November $24^{\text {th }}-28^{\text {th }}, 2008$ - Pucón, Chile

Plenary papers

importantly the data generated can be presented visually in a way that provides for easy interpretation of complicated datasets. It is likely that such models will have extensive application for understanding the relationships between soil chemical and physical variables on metal bioavailability, transformations, and the effects on soil microbial communities that carry out key ecosystem processes.

\section{Conclusions}

Aside from food chain transfer, the impact of metals and metalloids on microbial communities is one of the most serious concerns of heavy metal pollution of soils and can result in long term reduction in soil quality and primary productivity. Microbial communities can adapt to metal pollution, but loss of species diversity results in potential loss of biological functions and reduced soil resilience. The extent to which this occurs depends on soil physico-chemical properties that affect the bioavailability of metals. To this end, bioindicators of metal toxicity provide an integrative measure of the toxicities of metals in different soils. These relationships are only now being explored in detail and are complicated by the many interactions among the different variables that affect metal toxicities and microbial communities. New statistical modeling methods that employ artificial neural networks provide a means to sort out these interactions and develop hypotheses. Such models may also eventually be useful as decision support tools for land management of soils receiving heavy metal waste and for restoration of contaminated soils.

Keywords: Metal and metalloids; soil microbial diversity; contaminated soils.

\section{References}

T.H. Anderson and K.H. Domsch (1993). Soil Biol. Biochem. 25: 393-395

E. Baath and A. Frostegard et al. (1998). Ambio 27: 58-61.

I.V. Castro, E.M. Ferreira and S.P. McGrath. (2003). Soil Biol. Biochem. 35: 49-54.

D.H. Chang and S. Islam. (2000). Remote Sensing of the Environment 74: 534-544.

M.J. Conroy and B.R. Noon. (1996). Ecological Applications 6: 763-773.

D. De la Rosa, F. Mayol, E. Diaz-Pereira and M. Fernandez. (2004). Environmental Modeling Software 19: 929942.

P.J. Deadman and H.R. Gimblett. (1997. AI Applications 11: 107-112.

B.P. Degens, L.A. Schipper, G.P. Sparling and L.C. Duncan. (2001). Soil Biol. Biochem. 33: 1143-1153.

S. Dahlin, E. Witter et al. (1997). Soil Biol. Biochem. 29: 1405-1415.

P. Doelman, E. Jansen, M. Michels and M. van Til. (1994). Biol. Fert. Soils 17: 177-184.

Z. Filip. (2002). Agriculture, Ecosystems and Environment 88: 169-174.

F. Gil-Sotres, C. Trasar-Cepeda, M.C. Leiros and S. Seoane. (2005). Soil Biol. Biochem. 37:877-887.

B.S. Griffiths, K. Ritz, R.D. Bardgett, R. Cook, S. Christensen et al. (2000). Oikos 90: 279-294.

B.S. Griffiths, M. Bonkowski, J. Roy, K. Ritz. (2001). Appl. Soil Ecol. 16: 49-61.

C. Kampichler, S. Dzeroski, R. Wieland. (2000). Soil Biol. Biochem. 32: 197-209.

P. Legendre and M.J. Anderson. (1999). Ecological Monographs 69: 512-512.

E.R. Levine, D.S. Kimes and V.G. Sigillito. (1996). Ecological Modelling 92: 101-108.

J.M. Lynch. (2002). Biodegradation 13: 21-27.

P. Mele and D.E. Crowley. (2008). Agric. Ecosyst. Environ. 126: 139-152.

M.N. Neilson and A. Winding. (2002). Microorganisms as indicators of soil health. National Environmental Research Institute, Denmark, 83 pp. 

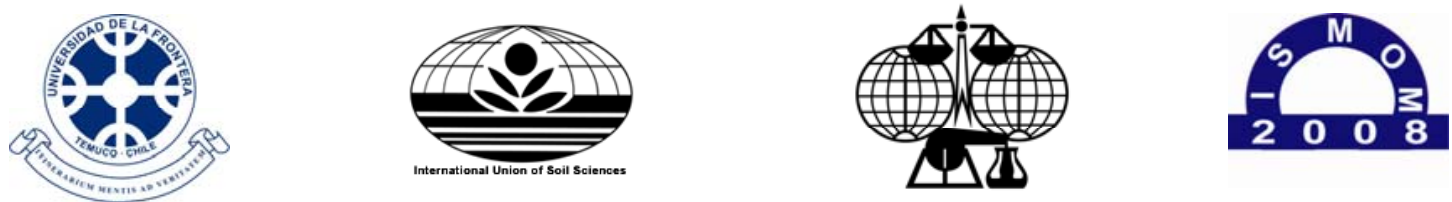

$5^{\text {th }}$ International Symposium ISMOM 2008 - November $24^{\text {th }}-28^{\text {th }}, 2008$ - Pucón, Chile

\section{Plenary papers}

P.A. Noble, J.S. Almeida and C.R. Lovell. (2000). Appl. Environ. Microbiol. 66: 694-699.

R.M. Patel, S.O. Prasher, P.K. Goel and R. Bassi. (2002). J. Am. Water Res. Assoc. 38: 91-100.

Z. Ramadan, P.K. Hopke, M.J. Johnson and K.M. Scow. (2005). Chemo. Intell. Lab. Sys 75: 23-30.

A. Schultz and R. Rieland. (1997). Comp. Electr. Agric. 18: 73-90.

R.E. Sojka and D.R. Upchurch. (1999). Soil Sci. Soc. Am. J. 63: 1039-1054.

S. Somaratne, G. Seneviratne and U. Coomaraswamy. (2005). Soil Sci. Soc. Am. J. 69: 1580-1589.

S. Tandy, V.L. Barbosa, A. Tye, S. Preston, G.I. Paton et al. (2005). Environ. Toxicol. Chem. 24: 530-536.

S.S. Tan and F.E. Smeins. ( 1996). Ecol. Model. 84: 91-97.

L.T. Tran, C.G. Knight, R.V. O'Neill, E.R. Smith and M. O'Connell, M. (2003). Environ. Manag. 31: 822-835.

P. vanBeelen and P. Doelman, P. (1997). Chemosphere 34: 455-499.

J. Winder. (2003). Soil quality monitoring programs: A literature review. In: Alberta Environmentally Sustainable Agriculture (AESA) Soil Quality Monitoring Program. Alberta Agriculture, Food and Rural development, Conservation Branch, No. 206, 7000-113 St. Edmonton Alberta Canada T6H 5 T6. 